RESPONSIBILITY IN THE CARE OF INEBRIATES.

We have received copies of a New Zealand newspaper (The Press of November last), giving an account of the case of McFarland $v$. Stewart, tried before Mr. Justice Denmiston. The defendant had received the plaintiff's husband into his home for inebriates at Opawa, while he was in a state of delirium tremens. Apparently he had made a rapid recovery from his mental troubles, but within a few days of his reception found a pea-rifle in the hall, got a cartridge in the lavatory, and shot himself in the absence of the defendant's son, who had been instructed to look after him. He had previously, while still mentally affected, tried to cut his throat with a knife. The action was brought under the Deaths by Accident Compensation Act, 1880 , to recover damages on behalf of the widow, and it was admitted that seven guineas a week was to be paid, as the patient required two attendants. The judge gave his decision in favour of Dr. Stewart, on the ground that no such negligence had been shown as would have entitled the deceased man to recover damages if he had merely wounded himself. As he had so much improved, the defendant was justified in relaxing supervision in the patient's interests. Some of the medical witnesses gave their opinion that the patient was sane when he took his life, and this also influenced the judge. The Press, however, expresses the feeling that the state of matters disclosed by the evidence is unsatisfactory. It is not satisfied that inebriates should be placed in private homes not subject to Government inspection, and animadverts on the dangerous nature of the weapons within easy reach, and on the facility with which the patient got whisky when he asked for it. It would appear that the Government has done nothing to provide institutions for the reception of habitual drunkards under their Inebriate Institutions Act of 1808 . This is much in accordance with our experience at home, and The Press, in urging for the due application of the existing law with reference to the insane in private houses, makes the same demand as we have repeatedly found necessary here. Apparently insane persons are being kept in private houses which are not licensed under the Lunatics Act, and of which the Government has no official cognizance. In a new country special difficulties exist in meeting the wants of the insane of all classes, and for that and other reasons it is desirable that facilities for proper treatment should exist; but while interposing no incapacitating difficulties in the way of developing public and private asylums and suitable houses for single care, the Government should insist on knowing where every person of unsound mind is kept for gain. We firmly believe that the best results for the patients and for the public are to be gained by a system of healthy competition under the inspection of capable physicians. The haphazard methods which permit of acute alcoholic cases having access to sharp knives and loaded firearms constitute a grave scandal. The suicidal tendencies of such patients are well known, and their treatment by whisky as reported, although not unknown in less remote localities, will hardly bear repetition in far Opawa. We sometimes hear of the blessed facility in lawmaking in new countries, in disparagement of a slower legislative coach elsewhere ; but the duties and responsibilities of Parliament do not end with the eruption of brand-new Acts. The more onerous and the more important matter comes later in due enforcement by properly equipped executors.

\title{
ANTI-ALCOHOLIC SERUM.
}

The Paris Academy of Medicine is responsible for a newspaper sensation. At its meeting on the 26th December last, MM. Broca, Sapelier, and Thiébaut presented a paper on the discovery of an anti-alcoholic serum, and a committee has been appointed to investigate and report. The preliminary principle adopted by the authors is that in alcoholic intoxication, as in morphia intoxication, there is a period of gradual toleration, and of desire for the poison. Certain organic poisons form in the organism antitoxins representing elements of resistance to infection. These antitoxins injected into another organism place it in a position of similar resistance. The observers produced tolerance to alcohol in the horse by giving it by the mouth, and found that the serum of this horse injected into other animals rendered tolerant and fond of alcohol, produced in these animals a pronounced distaste to alcohol. M. Broca declares that the injections caused no 